\title{
Induction of apoptosis and CYP4A1 expression in Sprague-Dawley rats exposed to low doses of perfluorooctane sulfonate
}

\author{
Hyung-Sub Kim, Seung Jun Kwack, Eui Sik Han, Tae Seok Kang, Seung Hee Kim \\ and Soon Young Han
}

\begin{abstract}
Toxicological Evaluation and Research Department, National Institute of Food and Drug Safety Evaluation, Korea Food and Drug Administration, Osong Health Technology Administrstion Complex, 187 Osongsaengmyeong 2(i)-ro, Gangoe-myeon, Cheongwon-gun, Chungbuk 363-951, Korea
\end{abstract}

(Received December 27, 2010; Accepted January 29, 2011)

\begin{abstract}
In previous studies, perfluorooctane sulfonate (PFOS), an environmental organic compound, was reported to cause hepatotoxicity and hypolipidemia in rodents. However, the low dose toxicity of PFOS and the toxic mechanisms involved remain to be determined. To clarify the low dose toxicity and action mechanism in the target organ toxicity, Sprague-Dawley (SD) rats were orally administered with PFOS at the doses of $0,1.25,5,10 \mathrm{mg} / \mathrm{kg} / \mathrm{day}$ for 28 days. As a result, no death or abnormal symptoms were observed in all groups. The significant loss of mean body weight was observed in female rats treated with $10 \mathrm{mg} / \mathrm{kg}$ PFOS and the relative liver weight of $10 \mathrm{mg} / \mathrm{kg}$ PFOS-treated group was significantly greater compared to control. Histopathological examination revealed that fatty change was evident in the liver of male rats treated with PFOS $(5$ and $10 \mathrm{mg} / \mathrm{kg}$ ) and hypertrophy and cellular swellings in females at the dose of $10 \mathrm{mg} / \mathrm{kg}$, which showed different pattern of pathological lesions. In addition, we demonstrated the expression induction of hepatic caspase-3 and cytochrome P450 4A1 (CYP4A1) related with apoptosis and lipid metabolism, respectively. This study suggested that no-observed-adverseeffect level (NOAEL) of PFOS was $1.25 \mathrm{mg} / \mathrm{kg}$ in 28-day repeated toxicity study and, however, the toxic response showed gender differences. The possible toxic mechanism of PFOS was the induction of apoptosis and altering lipid metabolism which resulted in hepatotoxicity.
\end{abstract}

Key words: PFOS, General toxicity, Hepatotoxicity, Apoptosis, CYP4A1

\section{INTRODUCTION}

Since the 1950s perfluorooctane sulfonate (PFOS) and other perfluorinated alkyl acids (PFAAs) that metabolize into PFOS have been widely used for industrial applications that include carpet, floor polishes, coating approved for food contact and insecticide formulations (3M Company, 1999). Previous studies have revealed accumulation of PFOS in a variety of wildlife species including marine mammals, fishes and birds due to the widespread use and its chemical property which is resistant to environmental and metabolic degradation (Giesy and Kannan, 2000; Hansen et al., 2001; Kannan et al., 2001, 2002). Also, pharmacokinetic studies have shown that once absorbed PFOS is distributed and accumulat- ed in the serum and liver but poorly eliminated (Seacat et al., 2003). In rats, a serum elimination half-life of 7.5 days was reported after an oral treatment of PFOS (Johnson et al., 1979); in cynomolgus monkeys, a halflife of 200 days was described (Seacat et al., 2002); and in humans, a mean half-life of approximately 8.7 years was recently estimated from retired production workers (Thibodeaux et al., 2003).

Toxicological profiles of PFOS have been reported in several animal species on repeated dose toxicity, genotoxicity and developmental toxicity. In the rat subchronic study, Goldenthal et al. (1978a) administered CD rats dietary levels of $0,30,100,300,1,000$ or 3,000 ppm PFOS for 90 days. As a result, all of the rats in the 300, 1,000 and 3,000 ppm groups died. Death occurred between days

Correspondence: Hyung-Sub Kim (E-mail: vetkimhs@hotmail.com)

Soon Young Han (E-mail: soonyoungh@kfda.go.kr) 
13-25 and days 18-28 for the males and females, respectively, in the 300 ppm group. Similar evidence of cumulative toxicity was observed in primates after repeated dosing with PFOS in 90-day toxicity studies. Rhesus monkeys receiving $0.5,1.5$ or $4.5 \mathrm{mg} / \mathrm{kg} /$ day for 90 days showed lowering of total serum cholesterol and signs of liver toxicity at the $1.5 \mathrm{mg} / \mathrm{kg} /$ day dose level, and death occurred within 7 weeks in all monkeys in the $4.5 \mathrm{mg} / \mathrm{kg}$ / day dose-group (Goldenthal et al., 1978b).

Otherwise, developmental or reproductive toxicities have been rather clearly evaluated in laboratory rodents (Lau et al., 2003; Thibodeaux et al., 2003; Yahia et al., 2008). Timed-pregnant SD rats and CD-1 mice were given 1,5 , or $10 \mathrm{mg} / \mathrm{kg}$ PFOS by gavage daily beginning on GD 2 until term. In rats, significant deficits of maternal weight gain were seen in the 5 and $10 \mathrm{mg} / \mathrm{kg}$ PFOS groups. Lower maternal serum cholesterol and triglycerides were noted at $10 \mathrm{mg} / \mathrm{kg}$, but liver weights were unaffected. In mice, PFOS did not alter the maternal weight gain appreciably, although liver weight of the dams was markedly elevated in the 5 and $10 \mathrm{mg} / \mathrm{kg}$ groups. In contrast to rats, PFOS did not significantly affect the mouse fetal weight, although the incidence of fetal mortality was slightly increased in the $10 \mathrm{mg} / \mathrm{kg}$ group. And PFOS is generally considered non-genotoxic and non-mutagenic. However, the general toxicity data focused on low dose exposure has been insufficient, although there have been developmental toxicity studies exposed to low doses of PFOS.

In regard to toxic mechanisms, PFOS has been suggested to interfere with mitochondrial bioenergetics, gap junctional intercellular communication, and fatty acidprotein binding in livers and cause peroxisomal proliferation in rodents (Berthiaume and Wallace, 2002; Hu et al., 2002). Perfluorooctanoate (PFOA), another major perfluorooctanoate compound, induced apoptosis, as well as perturbed the cell cycle in vitro system (Shabalina et al., 1999) and also caused increased beta-oxidation of fatty acids, increases in several cytochrome P450 (CYP)mediated reactions and inhibition of the secretion of very low-density lipoproteins and cholesterol from the liver (Kennedy et al., 2004). Although PFOS is expected to cause similar toxic effects as PFOA, the possible toxic mechanisms remain to be unclear compared with PFOA.

Recently, Cui et al. (2009) demonstrated toxicological profiles based on histological study in only male SD rats administered with 5 and $20 \mathrm{mg} / \mathrm{kg}$ of PFOS. Although obvious pathological alterations were observed in rats dosed at $20 \mathrm{mg} / \mathrm{kg}$, all animals of the group died within 26 days and slight tumefaction and dark color were observed in the liver of $5 \mathrm{mg} / \mathrm{kg}$ group. Despite no- observed-adverse-effect level (NOAEL) of PFOS would be expected to be lower than $20 \mathrm{mg} / \mathrm{kg}$ in rodent repeated dose study based on previous reports, the available low dose toxicity profile of PFOS has been extremely limited. Short-term exposure to high doses of PFOS induces various metabolic changes and toxic responses, however, extrapolation of these findings to the long-term and low-dose exposures to which humans are subject is highly problematic (Qazi et al., 2010). Since additional experiments to investigate NOAEL and its toxic mechanism in the target organ are indispensable, SD rats were orally administered with $1.25,5$ and $10 \mathrm{mg} / \mathrm{kg}$ of PFOS for 28 days. In parallel, we focused on the involvement of apoptosis and CYP4A as toxic mechanisms in SD rats exposed to low doses of PFOS.

\section{MATERIALS AND METHODS}

\section{Animals husbandry and maintenance}

Five-week old male and female SD rats were purchased from Orient Bio Inc. (Gapyeong, Korea) and acclimated for 1 week prior to commencement of the study. Animals were randomly allocated to 4 groups, each consisting of 12 males and 12 females, housed in a room with barrier system, and maintained under following conditions: temperature of $23 \pm 1{ }^{\circ} \mathrm{C}$, relative humidity $55 \pm 5 \%$, and $12 \mathrm{hr}$ light-dark cycle. The animals were housed in plastic cages (three rats per cage) on soft chip bedding. The protocol for this study was approved by the committee of National Institute of Toxicological Research and rats were handled in an accredited Korea Food and Drug Administration animal facility in accordance with the AAALAC International Animal Care Policies (accredited unit; Korea Food and Drug Administration; Unit Number 000996).

\section{Chemicals and experimental design}

PFOS (Perfluorooctane sulfonic acid potassium salt, CAS No. 2795-39-3, > 98\% pure) obtained from Fluka was dissolved in dimethylsulfoxide (DMSO, $<0.1 \%$ ) and adjusted to $1.25,5$, and $10 \mathrm{mg} / \mathrm{kg}$ PFOS using saline. PFOS was administered to the animals by gavage at volume of $2 \mathrm{ml} / \mathrm{kg} /$ day for 28 days. DMSO and Hoechst 33258 were purchased from Sigma (St. Louis, MO, USA). Clinical signs were observed daily and body weight and food consumption were measured twice a week. Prior to an autopsy, blood samples were collected from abdominal aorta under carbon dioxide anesthesia after starvation.

\section{Cell culture and cytotoxicity assay}

HepG2 cells were cultured in DMEM (Gibco, Grand Island, NY, USA) medium supplemented with 10\% fetal 
Low dose toxicity of PFOS in SD rats

bovine serum (FBS; Gibco) and antibiotics (penicillin and streptomycin, Gibco) under a humidified atmosphere with $5 \% \mathrm{CO}_{2}$ at $37^{\circ} \mathrm{C}$. The cell cultures were incubated with serum-free media containing PFOS (1, 3, 10, 30, 100, $300,500$ and $1,000 \mu \mathrm{M})$ in 96 well plate. The cytotoxicity of PFOS for $24 \mathrm{hr}$ was quantified by MTT assay in HepG2 cells. After incubation with PFOS for $24 \mathrm{hr}$, MTT solution was added to each well.

\section{Detection of apoptosis by fluorescence microscopy}

The morphological characteristics associated with apoptosis were analyzed by fluorescence microscopy by staining cells with Hoechst 33258 DNA-binding dye. One day before treatment, cells were plated on $100 \mathrm{~mm}^{2}$ dishes and then were treated with PFOS in the absence of FBS. After $24 \mathrm{hr}$, cells were fixed with 4\% paraformaldehyde in phosphate buffered saline (PBS) for $15 \mathrm{~min}$, then rinsed with PBS and stained with $1.0 \mu \mathrm{g} / \mathrm{ml}$ Hoechst 33258 in the dark for $10 \mathrm{~min}$. Cells were observed for fluorescence and photographed using a digital camera (Nikon, Tokyo, Japan).

\section{Hematology, serum chemistry and urinalysis}

Whole blood was collected in EDTA-coated tubes and analyzed using ADVIA 120 analyzer (Bayer, UK) for following hematological parameters: total leukocyte count (WBC), erythrocyte count (RBC), platelet count, hemoglobin, hematocrit, mean corpuscular volume (MCV), mean corpuscular hemoglobin $(\mathrm{MCH})$, mean corpuscular hemoglobin concentration (MCHC), RBC distribution width (RDW) and mean platelet volume (MPV). The serum biochemistry parameters including aspartate transaminase (AST), alanine transaminase (ALT), alkaline phosphate (ALP), albumin, triglyceride (TG), gamma glutamyl transpeptidase ( $\mathrm{r}-\mathrm{GT}$ ) and creatinine were evaluated using an autoanalyzer (Prestige 24i, Boeki Medical System, Tokyo, Japan). Urine samples collected by refrigeratingmetabolic cages(Tecniplast, Buguggiate, Italy) were analyzed for $\mathrm{pH}$, protein, glucose, ketone body, nitrite, occult blood, bilirubin and leukocytes using dipsticks (Multisatix $10 \mathrm{SG}$, Bayer). Urine specific gravity was determined with a refractometer.

\section{Histopathology}

For light microscopy, following organs were excised, trimmed and weighed prior to fixation: adrenals; brain; pituitary; kidneys; heart; lung; spleen; liver; testes; epididymis; ovary; and uterus. All organs sampled were fixed in $10 \%$ neutral buffered formalin and were processed and embedded in paraffin, sectioned to the thickness of 5 $\mu \mathrm{M}$, and stained with hematoxylin and eosin (H\&E) for a microscopic examination (Olympus IX70, Tokyo, Japan).

\section{Western blot analysis}

Total proteins were isolated from tissue homogenates using protein extraction solution (iNtRON Biotechnology, Seongnam, Korea). Hepatic proteins $(25 \mu \mathrm{g})$ were separated by 10\% SDS-PAGE (Invitrogen, Carlsbad, CA, Italy), blotted onto a nitrocellulose membrane, blocked with 5\% skim milk and incubated with primary antibodies against anti-caspase-3 (1:500), CYP4A1 (1:1,000) or $\beta$-actin $(1: 1,000)$. The membranes were washed for 15 min with PBS containing $0.1 \%$ Tween-20 and incubated with horseradish peroxidase-conjugated anti-goat $(1: 1,000)$ or anti-mouse $\operatorname{IgG}(1: 1,000)$. The blots were detected with ECL plus chemiluminescent detection reagent (Amersham Biosciences, Little Chalfont, UK).

\section{RNA extraction and quantitative real-time PCR}

Total RNA was extracted from frozen livers using TRIzol Reagent (Invitrogen) according to the manufacturer's protocol. Quantitative real-time PCR was performed by addition of Universal PCR Buffer and TaqMan primer/probe assay reagent specific for CYP4A1. All probes were purchased from Applied Biosystems as Assay-onDemand $^{\mathrm{TM}}$ Gene Expression Products (TaqMan MGB, FAM dye-labeled). Thermal cycling was performed with a real-time sequence detection plateform (ABI Prism 7500, Applied Biosystems, Foster City, CA, USA) with cycling parameters of $50^{\circ} \mathrm{C}$ for 2 min for activation, $95^{\circ} \mathrm{C}$ for $10 \mathrm{~min}$, and 40 cycles of $95^{\circ} \mathrm{C}$ for $15 \mathrm{sec}$ and $60^{\circ} \mathrm{C}$ for $1 \mathrm{~min}$. The $\mathrm{Ct}$ values obtained for the genes were normalized to GAPDH, and the derived fold increases compared with the controls.

\section{TUNEL staining}

To detect apoptosis, paraffin-embedded sections were stained with terminal deoxynucleotidyl transferasemediated dUTP nick end-labeling (TUNEL) kits (Roche Diagnostics GmbH, Mannheim, Germany) according to the manufacturer's instructions. Then the sections were examined using light microscopy (Olympus IX70).

\section{Statistical analysis}

Statistical analyses were performed using SigmaStat package (Version 10, Systat software). Treatment effects were analyzed using one-way ANOVA, followed by Dunnett's tests. Data comparisons were considered significant if $p<0.05$. 


\section{H.-S. Kim et al.}

\section{RESULTS}

\section{General observations and body weight}

During the study, no remarkable changes in general appearance were observed and all rats survived until scheduled necropsy. Likewise, there were no significant differences in the body weight of male rats between control and treatment groups. However, in females, body weight significantly decreased in rats administered with $10 \mathrm{mg} / \mathrm{kg}$ PFOS in a time-dependent manner (Fig. 1).

\section{Hematology, clinical biochemistry and urinalysis}

The results of hematology and serum biochemical examinations are summarized in Tables 1 and 2. Triglyceride (TG) was significantly decreased by PFOS administration in male rats exposed to $10 \mathrm{mg} / \mathrm{kg}$. However, urine analysis results showed no statistically significant changes in urine parameters for any of the endpoints measured (data not shown) as well as hematological analysis (Table 2).

\section{Organ weights and histopathology}

Relative liver weight significantly was increased in both male and female rats administered with $10 \mathrm{mg} / \mathrm{kg}$ PFOS $(p<0.05)$, however, the relative kidney weight was not changed (Fig. 2). All other relative organ weights measured of both male and female rats were not affected by doses of PFOS up to $10 \mathrm{mg} / \mathrm{kg}$ for 28 days. The histopathological study revealed morphological alterations mainly in the liver tissue due to the treatment with PFOS, however, it showed gender differences (Table 3). In the liver of male rats, the presence of fatty change was observed in a dose-dependent manner (Fig. 3B). Hepat- ic hypertrophy and cellular swellings were clearly detected in $10 \mathrm{mg} / \mathrm{kg}$ PFOS-treated female rats. Except livers, there was no significant change in the incidence between control and PFOS-treated groups.

\section{TUNEL assay and caspase-3 cleavage}

To investigate whether PFOS induces apoptosis in the rat liver, the tissue sections were labeled with an in situ TUNEL assay. Apoptotic signals were markedly observed in the liver of rat administered with $10 \mathrm{mg} / \mathrm{kg}$ PFOS compared to control group (Figs. 3C and D). To examine the involvement of caspase pathway in the apoptosis, Western blot analysis for procaspase-3 was carried out. As a result, we observed marked decrease in the expression of procaspase- 3 protein in the groups of PFOS treatment as the result of TUNEL assay (Fig. 4).

\section{Hoechst 33258 staining}

To determine the concentration of PFOS-treatment, cell viability was measured using the MTT assay in HepG2 cells. The cell viability was decreased dose-dependently in HepG2 cells and no significant cytotoxicity was not observed by $30 \mu \mathrm{M}$ PFOS following $24 \mathrm{hr}$ treatment. To characterize the involvement of the apoptotic process in the cell death by PFOS, we analyzed cells by staining with Hoechst 33258 dye. An increased incidence of profound chromatin condensation and nuclear fragmentation was observed in HepG2 cells treated with $30 \mu \mathrm{M}$ of PFOS (Fig. 5B), however, vehicle control group did not induced these morphological changes relating to apoptosis triggered by PFOS (Fig. 5A).

\section{(B)}

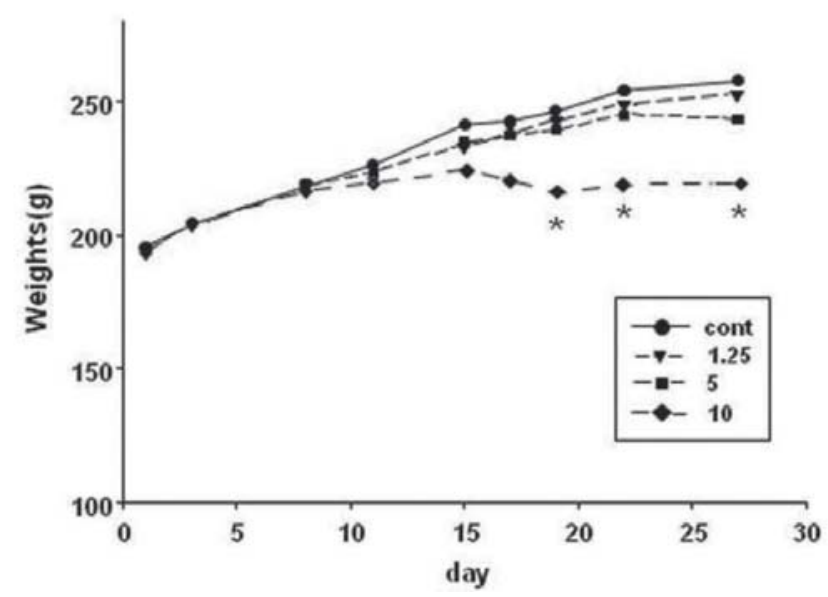

Fig. 1. Body weight change in SD rats administered with PFOS $(0,1.25,5,10 \mathrm{mg} / \mathrm{kg})$ for 4 weeks. (A), male; (B), female. 
Low dose toxicity of PFOS in SD rats

Table 1. Serum biochemical values of SD rats administered with PFOS for 4 weeks

\begin{tabular}{lcccc}
\hline Males & 0 & $1.25 \mathrm{mg} / \mathrm{kg}$ & $5 \mathrm{mg} / \mathrm{kg}$ & $10 \mathrm{mg} / \mathrm{kg}$ \\
\hline AST (IU/l) & $56.8 \pm 16.4$ & $64.2 \pm 18.2$ & $63.9 \pm 12.8$ & $89.4 \pm 7.7^{*}$ \\
ALT (IU/1) & $41.0 \pm 6.5$ & $46.7 \pm 13.3$ & $47.8 \pm 11.8$ & $58.4 \pm 17.0$ \\
ALP (IU/l) & $170.8 \pm 26.5$ & $164.2 \pm 31.7$ & $187.8 \pm 45.5$ & $244.3 \pm 45.7$ \\
$\gamma$-GT (IU/l) & $1.75 \pm 0.71$ & $1.50 \pm 0.55$ & $1.67 \pm 0.82$ & $1.62 \pm 0.74$ \\
CRE (mg/dl) & $1.25 \pm 0.08$ & $1.27 \pm 0.10$ & $1.31 \pm 0.08$ & $1.15 \pm 0.10$ \\
TG (mg/dl) & $58.7 \pm 34.8$ & $59.9 \pm 19.8$ & $30.8 \pm 14.2$ & $12.9 \pm 3.4 *$ \\
ALB (g/dl) & $4.11 \pm 0.19$ & $3.56 \pm 1.32$ & $4.13 \pm 0.16$ & $3.99 \pm 0.23$ \\
\hline Females & 0 & $1.25 \mathrm{mg} / \mathrm{kg}$ & $5 \mathrm{mg} / \mathrm{kg}$ & $10 \mathrm{mg} / \mathrm{kg}$ \\
\hline AST (IU/l) & $80.8 \pm 14.1$ & $43.1 \pm 17.5 *$ & $70.1 \pm 19.9$ & $87.3 \pm 3.9$ \\
ALT (IU/l) & $26.3 \pm 3.9$ & $36.5 \pm 6.3$ & $43.0 \pm 9.9$ & $49.3 \pm 17.9$ \\
ALP (IU/l) & $101.3 \pm 31.3$ & $87.1 \pm 13.5$ & $121.3 \pm 25.3$ & $141.1 \pm 27.9$ \\
$\gamma$-GT (IU/l) & $2.17 \pm 0.8$ & $1.86 \pm 0.9$ & $2.17 \pm 0.9$ & $2.12 \pm 0.9$ \\
CRE (mg/d) & $1.23 \pm 0.08$ & $1.31 \pm 0.09$ & $1.28 \pm 0.07$ & $1.35 \pm 0.09$ \\
TG (mg/dl) & $26.8 \pm 6.4$ & $36.2 \pm 6.4$ & $33.4 \pm 9.7$ & $26.0 \pm 9.2$ \\
ALB (g/dl) & $4.27 \pm 0.27$ & $4.38 \pm 0.16$ & $4.27 \pm 0.21$ & $4.55 \pm 0.26$ \\
\hline
\end{tabular}

*, Significantly different from the control group at the level of $p<0.05$.

Table 2. Hematological findings for SD rats administered with PFOS for 4 weeks $(\mathrm{n}=8 \sim 10)$

\begin{tabular}{|c|c|c|c|c|}
\hline Males & 0 & $1.25 \mathrm{mg} / \mathrm{kg}$ & $5 \mathrm{mg} / \mathrm{kg}$ & $10 \mathrm{mg} / \mathrm{kg}$ \\
\hline WBC $\left(10^{3} / \mathrm{mm}\right)$ & $9.4 \pm 2.3$ & $10.2 \pm 3.7$ & $10.6 \pm 2.4$ & $11.4 \pm 3.4$ \\
\hline $\mathrm{RBC}\left(10^{6} / \mathrm{mm}\right)$ & $8.1 \pm 0.6$ & $8.4 \pm 0.6$ & $7.9 \pm 0.3$ & $7.6 \pm 0.9$ \\
\hline Hemoglobin (g/dl) & $16.2 \pm 1.2$ & $17.1 \pm 1.1$ & $16.5 \pm 0.7$ & $15.4 \pm 1.9$ \\
\hline Hematocrit (\%) & $47.4 \pm 4.5$ & $49.9 \pm 4.0$ & $47.5 \pm 2.1$ & $47.5 \pm 3.3$ \\
\hline $\operatorname{MCV}(\mathrm{fl})$ & $58.6 \pm 2.2$ & $59.1 \pm 1.6$ & $60.5 \pm 1.3$ & $59.4 \pm 1.3$ \\
\hline $\mathrm{MCH}(\mathrm{pg})$ & $20.0 \pm 0.5$ & $20.3 \pm 0.4$ & $21.0 \pm 0.3$ & $20.3 \pm 0.5$ \\
\hline $\mathrm{MCHC}(\%)$ & $34.2 \pm 1.0$ & $34.3 \pm 0.8$ & $34.7 \pm 0.6$ & $34.3 \pm 0.9$ \\
\hline RDW (\%) & $11.5 \pm 0.4$ & $11.5 \pm 0.4$ & $11.9 \pm 0.4$ & $11.5 \pm 0.4$ \\
\hline MPV (fl) & $7.6 \pm 0.6$ & $8.1 \pm 0.5$ & $8.2 \pm 0.3$ & $8.6 \pm 0.5$ \\
\hline Platelet $\left(10^{4} / \mathrm{ul}\right)$ & $105 \pm 11.8$ & $93 \pm 14.2$ & $95 \pm 14.7$ & $108 \pm 13.2$ \\
\hline Females & 0 & $1.25 \mathrm{mg} / \mathrm{kg}$ & $5 \mathrm{mg} / \mathrm{kg}$ & $10 \mathrm{mg} / \mathrm{kg}$ \\
\hline WBC $\left(10^{3} / \mathrm{mm}\right)$ & $7.6 \pm 1.8$ & $8.3 \pm 3.0$ & $9.4 \pm 3.6$ & $8.5 \pm 2.6$ \\
\hline $\mathrm{RBC}\left(10^{6} / \mathrm{mm}\right)$ & $7.6 \pm 0.2$ & $7.8 \pm 0.4$ & $7.7 \pm 0.3$ & $7.7 \pm 0.5$ \\
\hline Hemoglobin (g/dl) & $15.6 \pm 0.5$ & $16.0 \pm 0.8$ & $16.1 \pm 0.6$ & $15.4 \pm 1.0$ \\
\hline Hematocrit (\%) & $43.1 \pm 1.9$ & $45.1 \pm 2.2$ & $44.4 \pm 2.5$ & $42.7 \pm 2.9$ \\
\hline $\operatorname{MCV}(\mathrm{fl})$ & $57.0 \pm 0.9$ & $58.2 \pm 1.9$ & $57.8 \pm 1.9$ & $55.5 \pm 1.1$ \\
\hline $\mathrm{MCH}(\mathrm{pg})$ & $20.6 \pm 0.4$ & $20.6 \pm 0.7$ & $21.0 \pm 0.4$ & $20.0 \pm 0.4$ \\
\hline $\mathrm{MCHC}(\%)$ & $36.1 \pm 0.7$ & $35.3 \pm 1.1$ & $36.4 \pm 1.0$ & $36.0 \pm 0.6$ \\
\hline RDW (\%) & $10.5 \pm 0.4$ & $10.8 \pm 0.3$ & $10.6 \pm 0.4$ & $10.5 \pm 0.6$ \\
\hline MPV (fl) & $7.0 \pm 0.7$ & $7.6 \pm 0.2$ & $7.9 \pm 0.3$ & $7.5 \pm 2.8$ \\
\hline Platelet $\left(10^{4} / \mathrm{ul}\right)$ & $99 \pm 5.4$ & $105 \pm 13.8$ & $112 \pm 8.6$ & $113 \pm 13.4$ \\
\hline
\end{tabular}


(A)

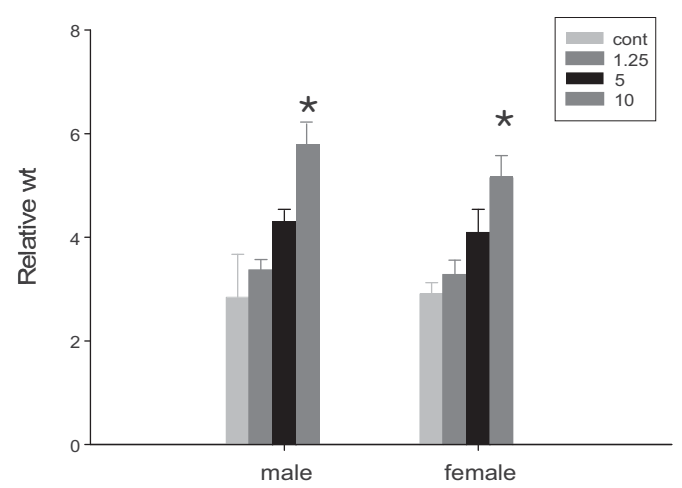

(B)

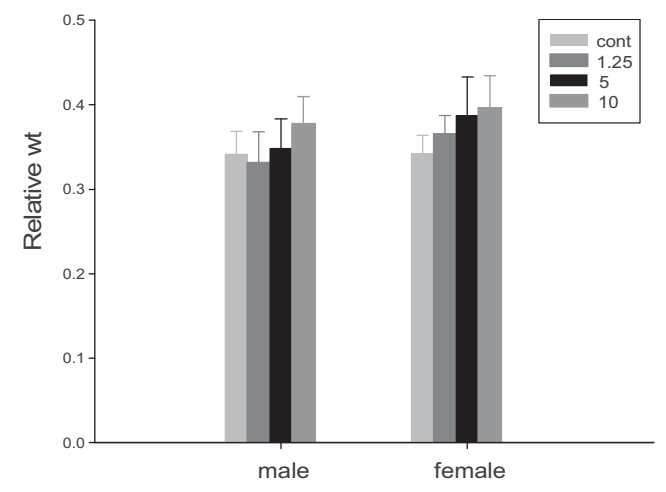

Fig. 2. Relative weight of liver (A) and kidney (B) in SD rats administered with PFOS for 4 weeks.

Table 3. Histopathological findings for SD rats exposed to PFOS for 4 weeks

\begin{tabular}{|c|c|c|c|c|c|c|c|c|}
\hline \multirow[b]{2}{*}{ Dose of PFOS (mg/kg/day) } & \multicolumn{4}{|c|}{ Males } & \multicolumn{4}{|c|}{ Females } \\
\hline & 0 & 1.25 & 5 & 10 & 0 & 1.25 & 5 & 10 \\
\hline \multicolumn{9}{|l|}{ Liver } \\
\hline Hypertrophy & 0 & 0 & 0 & 0 & 0 & 0 & 0 & $8^{\mathrm{a}}(67)^{\mathrm{b}}$ \\
\hline Necrosis & $1(8)$ & $1(8)$ & 0 & $2(17)$ & 0 & 0 & 0 & 0 \\
\hline Microgranuloma & 0 & $1(8)$ & 0 & $2(17)$ & 0 & 0 & 0 & 0 \\
\hline Fatty change & 0 & 0 & $4(33)$ & $8(67)$ & 0 & 0 & 0 & 0 \\
\hline Cellular swelling & 0 & 0 & 0 & 0 & 0 & 0 & 0 & $6(50)$ \\
\hline \multicolumn{9}{|l|}{ Kidney } \\
\hline Tubular basophilia & $2(17)$ & $2(17)$ & $3(25)$ & $1(8)$ & 0 & 0 & 0 & 0 \\
\hline \multicolumn{9}{|l|}{ Spleen } \\
\hline Fibrosis & 0 & $1(8)$ & 0 & 0 & 0 & 0 & 0 & 0 \\
\hline \multicolumn{9}{|l|}{ Epididymis } \\
\hline Focal inflammation & 0 & 0 & $1(8)$ & 0 & 0 & 0 & 0 & 0 \\
\hline \multicolumn{9}{|l|}{ Uterus } \\
\hline Dilatation & 0 & 0 & 0 & 0 & $1(8)$ & 0 & $4(33)$ & $1(8)$ \\
\hline
\end{tabular}

${ }^{a}$ Number of animal with lesion

${ }^{b}$ Values are processed as percentage

\section{Expressions of CYP4A1 mRNA and protein in the liver}

The effect of PFOS on CYP4A1 mRNA and protein expression was investigated, and GAPDH and $\beta$-actin were used as internal reference genes, respectively. PFOS significantly induced expression level of hepatic CYP4A1 mRNA at the doses of 5 and $10 \mathrm{mg} / \mathrm{kg}$ (Fig. 6B). In addition, the expression of CYP4A1 protein also increased in a dose-dependent manner (Fig. 6A).

\section{DISCUSSION}

Toxicological evaluations by repeated dose studies have been generally accepted, which has been advocated as a fundamental test for safety assessment. Although there have been previous reports on the toxicological profile of PFOS, however, available toxicological profiles of low dose PFOS including NOAEL have been limited.

In a recent, Cui et al. (2009) has clearly demonstrated histopathological observations and distribution results 

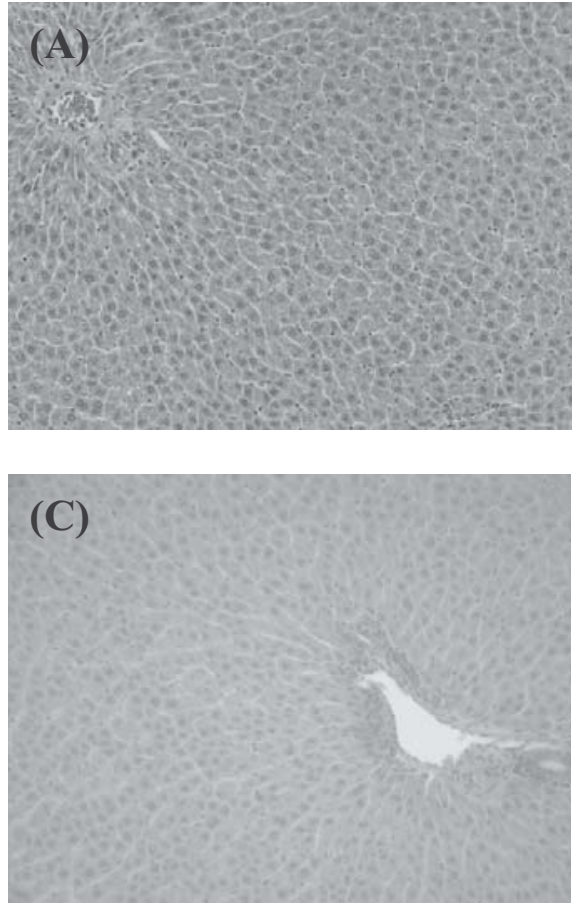
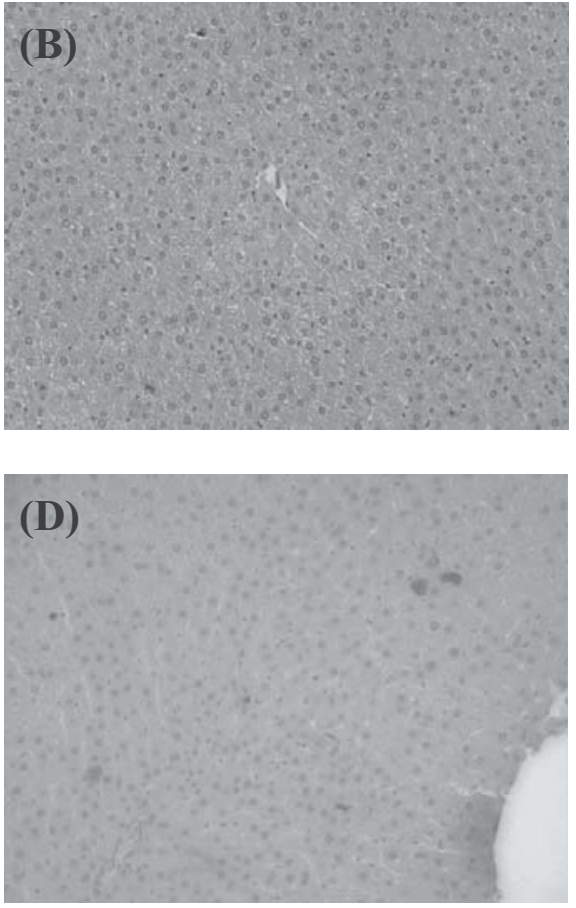

Fig. 3. Representative photographs of liver sections from the vehicle control (A and C) and $10 \mathrm{mg} / \mathrm{kg}$ PFOS (B and D) stained with hematoxylin-eosin (A and B) and TUNEL (C and D) in male rats (X100).

A

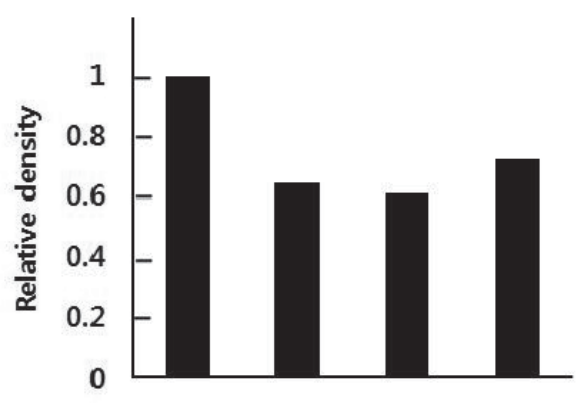

B

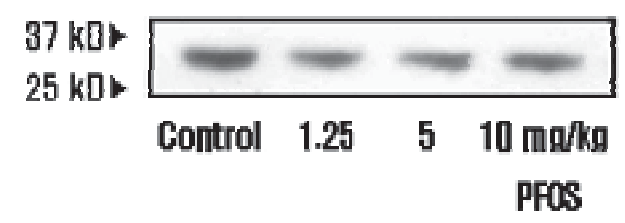

Fig. 4. Decrease of procaspase-3 expression in the liver of male SD rat exposed to PFOS. A, Densitometry analysis of procaspase- 3 expression. B, Western blot analysis for procaspase-3 in the liver of SD rat. Western blot analysis for procaspase- 3 showed a similar result between caspase cleavage and TUNEL staining. Details are described in Materials and Methods. in only male SD rats administered with two doses of PFOS (5 and $20 \mathrm{mg} / \mathrm{kg} /$ day for 4 weeks). Although obvious pathological alterations were observed in rats dosed at $20 \mathrm{mg} / \mathrm{kg}$, all animals of the group died within 26 days and slight tumefaction and dark color were observed in the liver of $5 \mathrm{mg} / \mathrm{kg}$ PFOS-treated group (Cui et al., 2009). There is another report on consecutive low dose treatment study of PFOS, which was focused on neuroendocrine effects (Austin et al., 2003). They have reported that PFOS induced significant body weight loss and increased norepinephrine concentrations in the paraventricular nucleus of the hypothalamus at dose of $10 \mathrm{mg} /$ $\mathrm{kg}$ in the female rats. But, they used intraperitoneal route and exposed for 14 days, relatively short period, resulted in no significant changes was observed at the lower dose of $1 \mathrm{mg} / \mathrm{kg}$ PFOS in the parameters measured. One of the early study on subchronic toxicity published over 30 years ago showed the toxicity exposed to 0, 30, 100, $300,1,000$ or 3,000 ppm PFOS by feed. All of the rats in $300,1,000$ and 3,000 ppm groups died due to high dosing (Goldenthal et al., 1978a). Since toxicological profiles of low dose PFOS in rodent repeated dose studies have been unclear, we aimed to demonstrate NOAEL of PFOS at low doses ranging from 1.25 to $10 \mathrm{mg} / \mathrm{kg}$. During the study, body weights significantly decreased only 

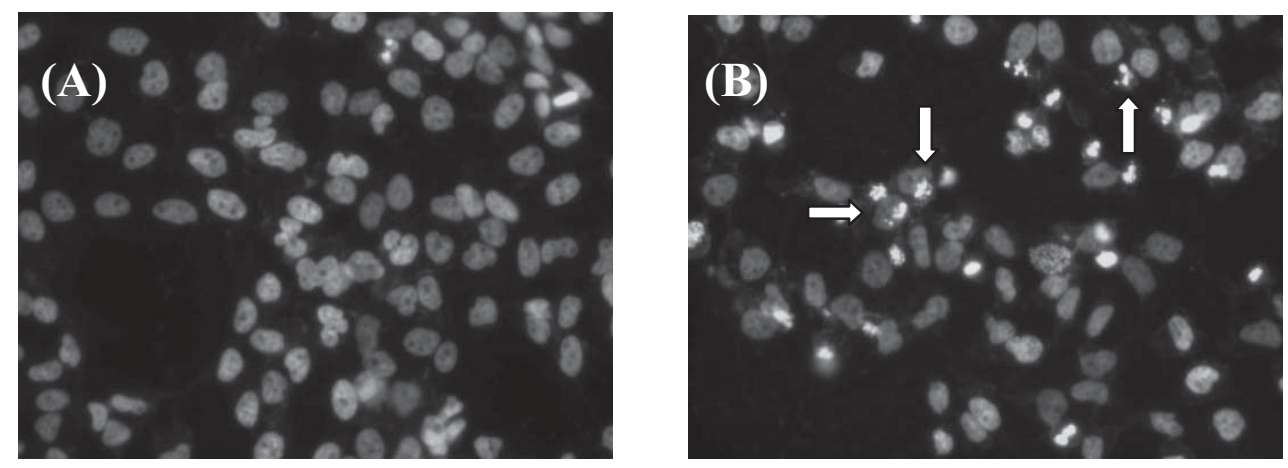

Fig. 5. Apoptotic morphological changes of nuclei in HepG2 cells treated with PFOS for $24 \mathrm{hr}$. HepG2 cells were exposed to test compounds and nuclear condensation was monitored with Hoechst 33258 staining as described in Materials and Methods. (A) Vehicle control; (B) $30 \mu \mathrm{M}$ PFOS. Arrows indicate apoptotic features of chromatin condensation. Magnification $100 \times$.

(A)

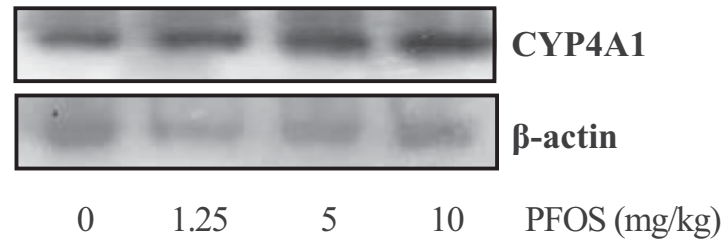

(B)

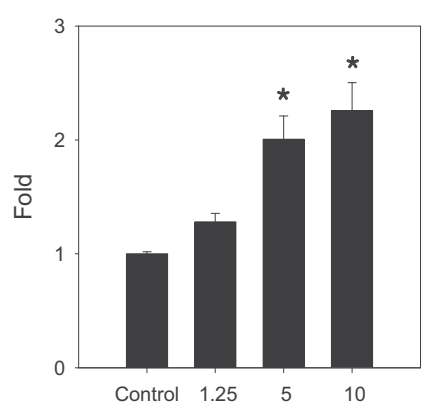

Fig. 6. The expression levels of CYP4A1 protein (A) and mRNA (B) in male rat livers exposed to PFOS.

in $10 \mathrm{mg} / \mathrm{kg}$-exposed female rats (Fig. 1). Since food consumption was significantly reduced at the dose of 10 $\mathrm{mg} / \mathrm{kg}$ PFOS, this body weight decrease partially corresponded to the reduction in food intake as reported previously (data not shown). In serum biochemistry examinations, the significant elevation of AST and significant decrease in TG value was observed only in male rats exposed to $10 \mathrm{mg} / \mathrm{kg}$ PFOS (Table 1). These results were consistent that the associations between exposure and cholesterol and triglyceride levels have been observed
(Olsen et al., 2003). Also, it is plausible that PFOS modified lipid metabolism, it could be related to the reduced body weight (Apelberg et al., 2007). Histopathological findings revealed that fatty change was evident in the liver of male rats treated with 5 and $10 \mathrm{mg} / \mathrm{kg}$ PFOS. In contrast, hypertrophy and cellular swelling of hepatocytes were mostly observed only in the group of 10 $\mathrm{mg} / \mathrm{kg}$ PFOS-treated female rats, which showed different pattern of pathological lesions. According to the previous report on gender differences, centrilobular to midzonal cytoplasmic hypertrophy of hepatocytes and focal necrosis was observed in the liver and the incidence and relative severity were greater in the males, and three males and two females in the 100 ppm group died prior to scheduled sacrifice (Goldenthal et al., 1978a). In this study, we demonstrated the significant decrease of body weight only in highest female group $(10 \mathrm{mg} / \mathrm{kg})$ and different patterns of pathological lesions in the target organ in terms of gender difference and these results supported that NOAEL value was lower in the male rather than in females.

In order to investigate action mechanisms of PFOS in the target organ, we carried out microarray analysis using male liver samples. As a result, apoptosis and lipid/fatty acid metabolism-related genes were significantly changed by PFOS administration (fold change $>1.5$ ) (data not shown). Based on these results, to investigate whether PFOS induces apoptosis in the liver, we conducted in situ TUNEL assay and Western blot analysis for caspase-3. We demonstrated that PFOS induced apoptosis in the rat liver via caspase pathway (Figs. 3 and 4). In addition, to prove the involvement of apoptosis in vitro system, HepG2 cell line with a wide variety of signal responses to different kinds of drugs was exposed to PFOS. As a result, morphological changes such as chromatin con- 
Low dose toxicity of PFOS in SD rats

densation were observed in HepG2 cells exposed to $30 \mu \mathrm{M}$ PFOS (Fig. 5). Recently, it has been reported that 50-200 $\mu \mathrm{M}$ PFOS also induced dissipation of mitochondria membrane potential, boost ROS generation and affect genes expression of apoptotic regulators in HepG2 cells ( $\mathrm{Hu}$ and $\mathrm{Hu}, 2009)$. PFOS is a structurally diverse class of chemicals that induce hepatomegaly in rodents which is characterized by the subcellular proliferation of organelles such as smooth endoplasmic reticulum, mitochondria, but most notably peroxisomes (Kennedy et al., 2004; Vanden Huevel et al., 2006). Maggiora et al. (2010) demonstrated that peroxisome proliferator-activated receptor $\alpha(\mathrm{PPAR} \alpha)$ protein content increased in HepG2 cells treated with clofibrate, causing apoptosis and it may be concluded that PPAR $\alpha$ is chiefly related to apoptosis and PPAR $\gamma$ to cell proliferation.

PPARs and another nuclear receptors superfamily, liver $\mathrm{X}$ receptor, are particularly important as master regulators of lipid and lipoprotein metabolism (Li and Glass, 2004). The PPAR $\alpha$ agonist includes $\beta$-oxidation of fatty acid, increase in several CYP-mediated reactions, and inhibition of secretion of very low density lipoproteins and cholesterol from the liver. The reduction in serum TG, hypolipidemia, which was observed in this study was consistent to the previous reports. Hypolipidemic effects have been known as sensitive changes observed in response to PFOS exposure (Seacat et al., 2002; Thibodeaux et al., 2003). To figure out causes which are related with the hypolipidemia by PFOS, we examined CYP4A1, a major hepatic enzyme responsible for lipid metabolism. The result showed significant increase of CYP4A1 expression in a dose-dependent manner (Fig. 6). This result supports that PFOS induced the CYP4A1 isozyme, which resulted in disturbing lipid metabolism through the peroxisome proliferation in the rat liver.

In summary, exposure to low dose PFOS for 28 days led to body weight loss, an increase in relative liver weight, a decrease in the level of triglyceride and specific histopathological hepatic lesions as previously reported above $10 \mathrm{mg} / \mathrm{kg}$ PFOS. PFOS revealed a significant hepatotoxicity in SD rats at the dose level of 5 and $10 \mathrm{mg} / \mathrm{kg}$, however, the toxic response to PFOS showed the apparent gender difference. Finally, PFOS primarily affected liver by inducing apoptotic signals and CYP4A1 expression which might be a potent cause of blood hypolipidemia. Further study on other genes responsible for lipid metabolism is promising to elucidate the mechanism of hypolipidemia by PFOS-treatment and is needed to examine molecular mechanisms involved in gender differences.

\section{ACKNOWLEDGMENTS}

This research was supported by a grant from National Institute of Food and Drug Safety Evaluation, Korea Food and Drug Administration for the Korea National Toxicology Program (07141KFDA566 and 08151KFDA409).

\section{REFERENCES}

3M Company (1999): Fluorochemical use, distribution, and release overview. (A Report Prepared for the US EPA 1 March, 2000: EPA Docket \# OPPT-2002-0043). St. Paul, MN: 3M Company.

Apelberg, B.J., Witter, F.R., Herbstman, J.B., Calafat, A.M., Halden, R.U., Needham, L.L. and Goldman, L.R. (2007): Cord serum concentrations of perfluorooctane sulfonate (PFOS) and perfluorooctanoate (PFOA) in relation to weight and size at birth. Environ. Health Perspect., 115, 1670-1676.

Austin, M.E., Kasturi, B.S., Barber, M., Kannan, K., MohanKumar, P.S. and MohanKumar Sheba, M.J. (2003): Neuroendocrine effects of perfluorooctane sulfonate in rats. Environ. Health Perspect., 111, 1485-1489.

Berthiaume, J. and Wallace, K.B. (2002): Perfluorooctanoate, perfluorooctane sulfonate, and N-ethyl perfluoroctanesulfonamido ethanol; peroxisome proliferation and mitochondrial biogenesis. Toxicol. Lett., 129, 23-32.

Cui, L., Zhou, Q., Liao, C., Fu, J. and Jiang, G. (2009): Studies on the toxicological effects of PFOA and PFOS on rats using histological observation and chemical analysis. Arch. Environ. Contam. Toxicol., 56, 338-349.

Giesy, J.P. and Kannan, K. (2001): Global distribution of perfluorooctanesulfonate in wildlife. Environ. Sci. Technol., 35, 1339-1342.

Goldenthal, E.I., Jessup, D.C., Geil, R.G., Jefferson, N.D., Arceo, R.J. and Ruecker, F.A. (1978a): 90-day subacute rat study. Study No. 137-085. International Research and Development Corporation, Mattawan, MI. (U.S. EPA Docket No. 8(e)HQ-1180-00374.

Goldenthal, E.I., Jessup, D.C., Geil, R.G. and Mehring, J.S. (1978b): 90-day subacute rhesus monkey toxicity study. Study No. 137092. International Research and Development Corporation, Mattawan, MI. (U.S. EPA Docket No. 8(e)HQ-1180-00374.

Hansen, K.J., Clemen, L.A., Ellefson, M.E. and Johnson, H.O. (2001): Compound-specific, quantitative characterization of organic fluorochemicals in biological matrices. Environ. Sci. Technol., 35, 766-770.

Hu, W., Jones, P.D., Upham, B.L., Trosko, J.E., Lau, C. and Giesy, J.P. (2002): Inhibition of gap junctional intercellular communication by perfluorinated compounds in rat liver and dolphin kidney epithelial cell lines in vitro and Sprague-Dawley rats in vivo. Toxicol. Sci., 68, 429-436.

Hu, X.Z. and Hu, D. (2009): Effects of perfluorooctanate and perfluorooctane sulfonate exposure on hepatoma HepG2 cells. Arch. Toxicol., 83, 851-861.

Johnson, G.W., Gilson, S.J. and Ober, R.E. (1979): Absorption of $\mathrm{FC}-143-{ }^{14} \mathrm{C}$ in rats after a single oral dose, Riker Laboratoires Inc., St. Paul, MN.

Kannan, K., Franson, J.C., Bowerman, W.W., Hansen, K.J., Jones, P.D. and Giesy, J.P. (2001): Perfluorooctane sulfonate in fish-eating water birds including bald eagles and albatrosses. Environ. Sci. Technol., 35, 3065-3070.

Kannan, K., Crosolini, S., Falandysz, J., Oehme, G., Focardi, S. and 


\section{H.-S. Kim et al.}

Giesy, J.P. (2002): Perfluorooctanesulfonate and related fluorinated hydrocarbons in marine mammals, fishes, and birds from coasts of the Baltic and the Mediterranean Seas. Environ. Sci. Technol., 36, 3210-3216.

Kennedy, G.L.Jr., Butenhoff, J.L., Olsen, G.W., O’Conner, J.C., Seacat, A.M., Perkins, R.G., Biegel, L.B., Murphy, S.R. and Farrar, D.G. (2004): The toxicology of perfluorooctanoate. Crit. Rev. Toxicol., 34, 351-384.

Lau, C., Thibodeaux, J.R., Hanson, R.G., Rogers, J.M., Grey, B.E., Stanton, M.E., Butenhoff, J.L. and Stevenson, L.A. (2003): Exposure to perfluorooctane sulfonate during pregnancy in rat and mouse. II: Postnatal Evaluation. Toxicol. Sci., 74, 382-392.

Li, A.C. and Glass, C.K. (2004): PPAR- and LXR-dependent pathways controlling lipid metabolism and the development of atherosclerosis. J. Lipid Res., 45, 2161-2173.

Maggiora, M., Oraldi, M., Muzio, G. and Canuto, R.A. (2010): Involvement of PPAR $\alpha$ and PPAR $\gamma$ in apoptosis and proliferation of human hepatocarcinoma HepG2 cells. Cell Biochem. Funct., 28, 571-577.

Olsen, G.W., Burris, J.M., Burlew, M.M. and Mandel, J.H. (2003): Epidemic assessment of worker serum perfluorooctane sulfonate (PFOS) and perfluorooctanoate (PFOA) concentrations and medical surveillance examinations. J. Occup. Environ. Med., 45, 260-270

Qazi, M.R., Nelson, B.D., Depierre, J.W. and Abedi-Valugerdi, M. (2010): 28-Day dietary exposure of mice to a low total dose $(7 \mathrm{mg} / \mathrm{kg}$ ) of perfluorooctanesulfonate (PFOS) alters neither the cellular compositions of the thymus and spleen nor humoral immune responses: does the route of administration play a pivot- al role in PFOS-induced immunotoxicity? Toxicology, 267, 132139.

Seacat, A.M., Thomford, P.J., Hansen, K.J., Olsen, G.W., Case, M.T. and Butenhoff, J.L. (2002): Subchronic toxicity studies on perfluorooctanesulfonate potassium salt in cynomolgus monkeys. Toxicol. Sci., 68, 249-264.

Seacat, A.M., Thomford, P.J., Hansen, K.J., Olsen, G.W., Case, M.T. and Butenhoff, J.L. (2003): Sub-chronic dietary toxicity of potassium perfluorooctanesulfonate in rats. Toxicology, 183, 117-131.

Shabalina, I.G., Panaretakis, T., Bergstrand, A. and DePierre, J.W. (1999): Effects of the rodent peroxisome proliferators and hepatocarcinogen, perfluorooctanoic acid, on apoptosis in human hepatoma HepG2 cells. Carcinogenesis, 20, 2237-2246.

Thibodeaux, J.R., Hanson, R.G., Rogers, J.M., Grey, B.E., Barbee, B.D., Richards, J.H., Butenhoff, J.L., Stevenson, L.A. and Lau, C. (2003): Exposure to perfluorooctane sulfonate during pregnancy in rat and mouse. I: maternal and prenatal evaluations. Toxicol. Sci., 74, 369-381.

Vanden Heuvel, J.P., Thompson, J.T., Frame, S.R. and Gillies, P.J. (2006): Differential activation of nuclear receptors by perfluorinated fatty acid analogs and natural fatty acids: a comparison of human, mouse, and rat peroxisome proliferator-activated receptor-alpha, -beta, and -gamma, liver $\mathrm{X}$ receptor-beta, and retinoid $\mathrm{X}$ receptor-alpha. Toxicol. Sci., 92, 476-489.

Yahia, D., Tsukuba, C., Yoshida, M., and Sato, I. and Tsuda, S. (2008): Neonatal death of mice treated with perfluorooctane sulfonate. J. Toxicol. Sci., 33, 219-226. 